\title{
Ammonia detection by use of near-infrared diode-laser-based overtone spectroscopy
}

\author{
Ricardo Claps, Florian V. Englich, Darrin P. Leleux, Dirk Richter, Frank K. Tittel, and \\ Robert F. Curl
}

\begin{abstract}
We describe a portable diode-laser-based sensor for $\mathrm{NH}_{3}$ detection using vibrational overtone absorption spectroscopy at $1.53 \mu \mathrm{m}$. Use of fiber-coupled optical elements makes such a trace gas sensor rugged and easy to align. On-line data acquisition and processing requiring $<30 \mathrm{~s}$ can be performed with a laptop PC running LabVIEW software. The gas sensor was used primarily for $\mathrm{NH}_{3}$ concentration measurements with a sensitivity of 0.7 parts per million (signal-to-noise ratio of 3 ) over a two-week period in a bioreactor being developed at the NASA Johnson Space Center for water treatment technologies to support long-duration space missions. The feasibility of simultaneous, real-time measurements of $\mathrm{NH}_{3}$ and $\mathrm{CO}_{2}$ concentrations is also reported. (C) 2001 Optical Society of America
\end{abstract}

OCIS codes: $300.6360,140.3490,280.3420$.

\section{Introduction}

Laser-based spectroscopic techniques to detect trace gases sensitively and selectively in real time in the infrared (IR) spectral region have been the focus of considerable research and development activities in recent years. The principal optical gas sensor technologies are based on absorption spectroscopy of fundamental bands in the 3-25- $\mu \mathrm{m}$ spectral region and near-IR vibrational overtone and combination bands from 1-3 $\mu \mathrm{m}$. Common radiation sources include continuous-wave (cw) diode lasers (GaAs-based, antimonide-based, lead salt), parametric frequency conversion devices (difference frequency generation and optical parametric oscillators), gas lasers ( $\mathrm{CO}$ and $\mathrm{CO}_{2}$ ), and quantum-cascade lasers. Telecommunication distributed-feedback (DFB) diode lasers are ideally suited for overtone spectroscopy of molecules with chemical bonds such as $\mathrm{C}-\mathrm{H}, \mathrm{O}-\mathrm{H}$, and $\mathrm{N}-\mathrm{H}$ in the near-IR region $(0.78-2.5 \mu \mathrm{m})$. In this paper we employ them to develop a gas sensor suitable for simultaneous $\mathrm{NH}_{3}$ concentration measurements at

When this research was performed, all the authors were with the Rice Quantum Institute, Rice University, Houston, Texas 772511892. R. Claps (Ricardo.claps@radiantphotonics.com) is now with Radiant Photonics, Incorporated, 1908 Kramer Lane, Building B, Austin, Texas 78758. The e-mail address for F. K. Tittel is fkt@rice.edu.

Received 4 December 2000; revised manuscript received 17 April 2001.

0003-6935/01/244387-08\$15.00/0

(C) 2001 Optical Society of America the $1 \times 10^{-6}$ level with a precision of 0.2 parts per million (ppm) and $\mathrm{CO}_{2}$ measurements between 1000 and 20,000 ppm. The sensor was then used to monitor dynamic ammonia concentrations in bioreactor vent gases at the NASA Johnson Space Center (JSC). In addition, the performance characteristics of the bioreactor in terms of the water chemistry could be evaluated. Other applications for compact, realtime ammonia sensors include the monitoring of selective noncatalytic $\mathrm{NO}_{x}$ reduction processes, process control in semiconductor manufacturing, and environmental monitoring.

Ammonia has a rich spectrum in the near-IR region..$^{1-5}$ In the spectral range from 1450 to 1560 $\mathrm{nm}\left(\sim 6400-6900 \mathrm{~cm}^{-1}\right)$, Lundsberg-Nielsen et al. ${ }^{6}$ have identified 1710 ammonia absorption lines and assigned 381 of them to rotational-vibrational transitions in the combination band $v_{1}+v_{3}$ and the overtone $2 v_{3}$. Webber et al. ${ }^{7}$ examined these lines for interferences and pointed out the best lines for monitoring purposes. From their report, one of the lines at $1531.7 \mathrm{~nm}\left(6528.8 \mathrm{~cm}^{-1}\right)$ was chosen as the operating wavelength for the $\mathrm{NH}_{3}$ sensor described here. At this wavelength, low-noise InGaAs detectors are available that operate with quantum efficiencies close to unity and require no cooling or temperature control. Overtone spectroscopy exhibits absorption line strengths that are typically approximately 1-2 orders of magnitude weaker than those of the fundamental vibrations in the mid-IR. To obtain the required sensitivity in the near IR, longer absorption path lengths and optimal balancing of laser noise are 
Table 1. $\mathrm{NH}_{3}$ and $\mathrm{CO}_{2}$ Absorption Lines

\begin{tabular}{|c|c|c|c|c|c|}
\hline \multirow[b]{2}{*}{ Line } & \multicolumn{2}{|c|}{ Line Strength } & \multirow[b]{2}{*}{$\begin{array}{l}\text { Frequency } \\
\quad\left(\mathrm{cm}^{-1}\right)\end{array}$} & \multirow[b]{2}{*}{$\begin{array}{l}\text { Wavelength } \\
(\mathrm{nm})\end{array}$} & \multirow[b]{2}{*}{ Reference } \\
\hline & $\left(\mathrm{cm}^{-1} /\right.$ molecule $\left.\mathrm{cm}^{-2}\right)$ & $\begin{array}{c}{\left[\mathrm{cm}^{-1} /(\mathrm{atm} \mathrm{cm})\right]} \\
(\text { at } 296 \mathrm{~K})\end{array}$ & & & \\
\hline$A$ & $2.33 \times 10^{-21}$ & 0.057784 & 6528.76 & 1531.68 & 7 \\
\hline$B$ & $1.24 \times 10^{-21}$ & 0.0307 & 6528.89 & 1531.65 & 7 \\
\hline$C$ & $5.19 \times 10^{-25}$ & $1.29 \times 10^{-5}$ & 6528.895 & 1532.65 & 12 \\
\hline
\end{tabular}

required. For this purpose, a compact multipass cell configured for a 36-m total optical path-length and an autobalance detection technique was used. ${ }^{8}$ Other groups have used cavity-enhanced absorption spectroscopy to monitor rovibrational overtone and combination band transitions.9,10 Also, use of cryogenically cooled tunable diode lasers, covering the fundamental absorption band of $\mathrm{NH}_{3}\left(v_{2}\right.$, at 10.07 $\mu \mathrm{m})$, has been reported. ${ }^{11}$ The sensitivity obtained in all cases is comparable to that described in this paper, but those techniques have not yet been applied to a portable system that has proven its applicability and performance in the field.

The selection of a suitable isolated absorption line for the design of the gas sensor to be used for ammonia monitoring in the bioreactor depends on potential absorption interference by other gas species present in the system. In the bioreactor environment, in addition to $\mathrm{NH}_{3}$, the presence of $\mathrm{H}_{2} \mathrm{O}$ and $\mathrm{CO}_{2}$ needs to be considered. The line selected for this study has the merit of being more than $1 \mathrm{~cm}^{-1}$ away from the next $\mathrm{H}_{2} \mathrm{O}$ absorption line and approximately 0.13 $\mathrm{cm}^{-1}$ away from an adjacent $\mathrm{NH}_{3}$ and $\mathrm{CO}_{2}$ overtone transition, ${ }^{12}$ which permits simultaneous concentration measurements of $\mathrm{NH}_{3}$ and $\mathrm{CO}_{2}$ at $6528.9 \mathrm{~cm}^{-1}$.

An ammonia (or any other gas) concentration measurement for narrow-linewidth radiation sources is obtained with the Beer-Lambert absorption law, which relates the intensity of light entering into an absorption medium $I_{0}$ to the transmitted intensity $I$ as follows:

$$
\frac{I}{I_{0}}=\exp \left(-S_{\nu} \phi_{\nu} P \chi_{j} l\right),
$$

where $S_{v}$ is the temperature-dependent absorption line strength for a specific transition denoted by $v$ $\left[\mathrm{cm}^{-1}(\mathrm{~atm} / \mathrm{cm})\right], \phi_{\nu}$ is the line-shape function $(\mathrm{cm}), \chi_{j}$ is the fractional concentration of the species $j, P$ is pressure (atm), and $l$ is the optical path length through the medium $(\mathrm{cm})$.

Table 1 depicts the three absorption lines that are used in this study. Lines $A$ and $B$ are the two ammonia lines used: $A$ is an isolated line useful for the measurement of ammonia concentrations whereas the other ammonia line $B$ overlaps with line $C$, which is the $(00001) \leftarrow(30011), R(36)$ overtone transition of $\mathrm{CO}_{2}$.

The line-strength values reported in Table 1 correspond to a temperature of $296 \mathrm{~K}$. For measurements at the slightly higher temperatures used in the present study (between 300 and $313 \mathrm{~K}$ ), an increase in line strength of less than $4 \%$ is to be expected. ${ }^{6}$ The line strength of $C$ is approximately a factor of 5000 less than $A$. However, in the bioreactor exhaust, $\mathrm{CO}_{2}$ concentrations can be as high as $50 \%$ or more, with the result that line $A$ ends up buried within line $C$. On the other hand, if $\mathrm{CO}_{2}$ levels are below 3\%, overlapping between lines $A$ and $C$ is negligible and the ammonia concentration can easily be extracted with line $A$. Furthermore, under these conditions, the three lines $A, B$, and $C$ can be used to perform simultaneous $\mathrm{NH}_{3}$ and $\mathrm{CO}_{2}$ concentration measurements.

\section{Experimental}

\section{A. Ammonia Sensor}

The diode-laser-based gas sensor developed for online $\mathrm{NH}_{3}$ monitoring in a bioreactor system is shown in Fig. 1. Its main components are a fiber-coupled DFB diode laser (NLK1554STB from NTT Electronics Corporation, Japan), a compact 36-m multipass, astigmatically compensated Herriott cell and a dualbeam, autobalanced InGaAs detector (Nirvana 2017 from New Focus), which can also operate as a single photodetector. A two-stage diaphragm pump was used to flow the sample gas through the multipass cell at a pressure of 100 Torr. The multipass cell

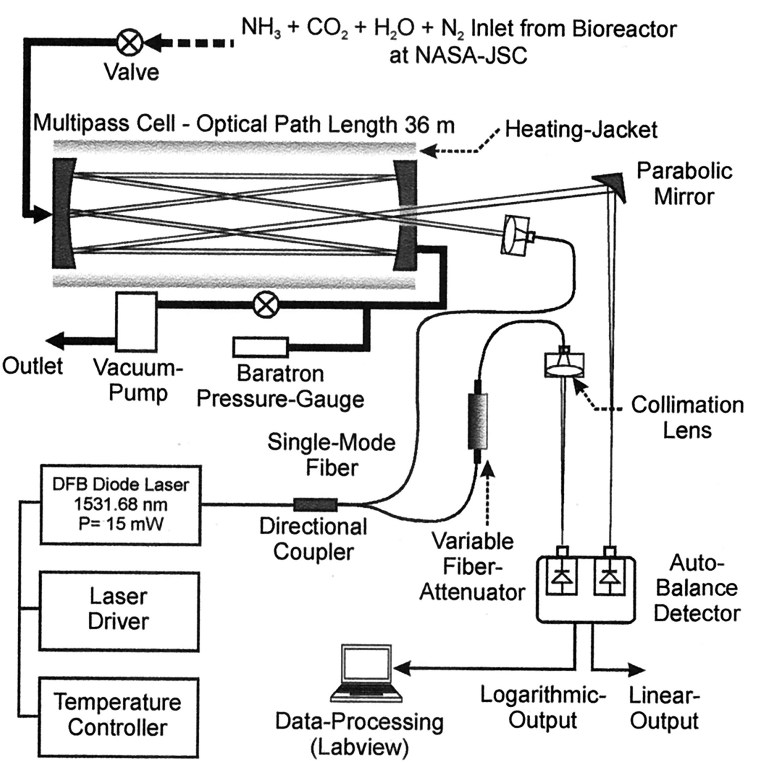

Fig. 1. Schematic of the DFB diode-laser-based ammonia sensor. 
was heated to a temperature of $40^{\circ} \mathrm{C}$ to minimize ammonia adsorption on its glass walls and to prevent potential water condensation on the cell mirrors.

The laser diode was driven by a compact current supply (MPL-250, Wavelength Electronics) with ripple noise $<1 \mu \mathrm{A}$ so that the frequency fluctuations of the laser line that are due to current noise are negligible $(<1 \mathrm{MHz})$. The current supply is scanned at $20 \mathrm{~Hz}$ about an average current of $67 \mathrm{~mA}$ with a sawtooth ramp function. The laser temperature was controlled to within $0.003{ }^{\circ} \mathrm{C}$, near $32{ }^{\circ} \mathrm{C}$, by a thermoelectric current driver (HTC-1500, Wavelength Electronics). The scan range of the laser under these conditions was $0.3 \mathrm{~cm}^{-1}$, which allowed all three spectral lines, $A, B$, and $C$, to be accessed on every scan.

The fiber-pigtailed DFB laser diode delivers 15 $\mathrm{mW}$ at $1531.7 \mathrm{~nm}$ with a specified linewidth of $<10$ $\mathrm{MHz}$. The fiber was fusion spliced to a 70/30(\%) directional coupler with an insertion loss of less than $2 \%$. The $70 \%$ power arm of the directional coupler was sent to the multipass cell by use of a lens ( $f=7 \mathrm{~mm}, 0.5$ N.A.) mounted in a precision holder with 5 deg of freedom (Optics for Research) to set the beam waist at the midpoint of the multipass cell. The $30 \%$ power arm was used as the reference beam for the balancing detector. This integrated laser and optical fiber configuration delivers $10 \mathrm{~mW}$ of laser light at the input of the multipass cell. The output power of the beam obtained from the cell after 182 passes was $17 \mu \mathrm{W}$, for a throughput efficiency of $0.17 \%$. This corresponds to a $96.5 \%$ reflectivity for the cell mirrors, indicating degradation from the original reflectivity of $98 \%$ after three years of use. The output beam from the cell is focused on the signal and reference photodiodes of the dual-beam detector by a gold-coated parabolic mirror of 1 -in. $(2.54-\mathrm{cm})$ diameter $(f=2)$ and a lens ( $f=7 \mathrm{~mm}, 0.5$ N.A.) mounted on a precision holder, respectively. Because the reference beam power $\left(P_{\text {ref }}\right)$ was much greater than the power of the signal beam coming from the cell $\left(P_{\text {signal }}\right)$, it was attenuated with a variable fiber attenuator. For optimum performance of the autobalanced detector, the reference power was set as $P_{\text {ref }}=2.2 \times P_{\text {signal }}$ at the center frequency of the laser scan. The attenuation level was set below 25 $\mathrm{dB}$, because above this level interference fringes from fiber-to-fiber etalons produced in the attenuator module started to affect the observed signal.

A laptop PC running LabVIEW 5.0 software was used for data acquisition and processing. In the autobalance mode, 500 scans were averaged for each single concentration measurement. For the concentration measurements made with the detector in the linear mode, 1000 scans were used for a single measurement because of the lower signal-tonoise ratio of this mode. The total data collection time, averaging, and processing to obtain a single concentration measurement is less than $30 \mathrm{~s}$. For convenience, the sensor was configured to take measurements every minute to correlate the ammonia

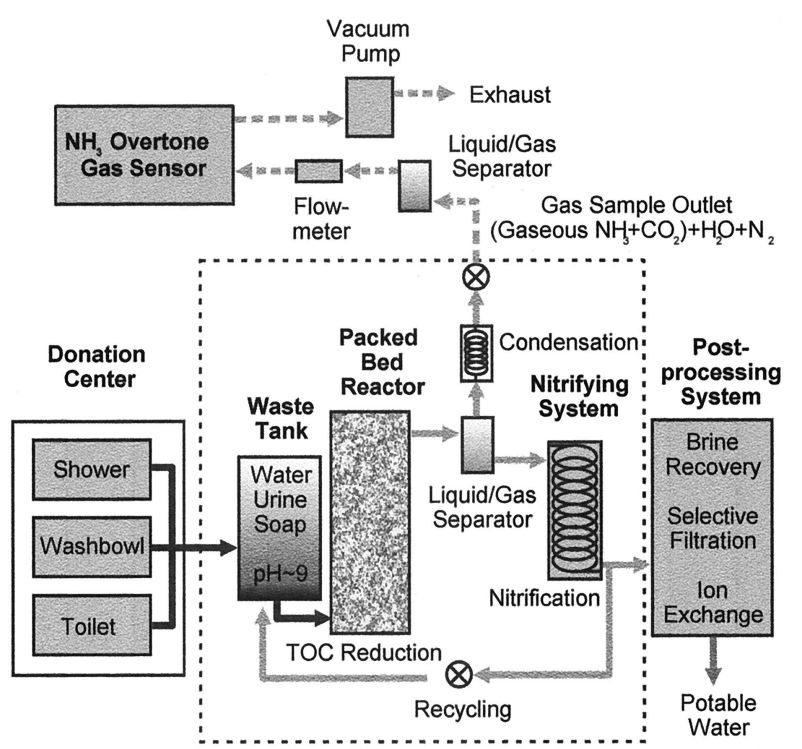

Fig. 2. Diagram depicting the main subsystems of the NASA JSC BWP system and attached $\mathrm{NH}_{3}$ diode-laser-based gas sensor. The actual size of the BWP is $2 \mathrm{~m} \times 2 \mathrm{~m} \times 3 \mathrm{~m}$.

measurements to external daily events and specific chemical actions performed on the bioreactor. We found it convenient to monitor the sensor performance and concentration data remotely using PC Anywhere software.

\section{B. Bioreactor and Measurement Setup}

The bioreactor referred to above is part of a water recovery system being developed at the JSC in Houston, Texas. The water recovery system is composed of several subsystems, among them the biological water processor (BWP), which is illustrated in Fig. 2. This system produces potable water from a wastewater stream using anaerobic microbial processes. Aqueous ammonia is produced in the BWP and must be removed to preserve the bacterial population. This is done at the nitrifier stage of the system, where ammonia is oxidized into $\mathrm{NO}_{3}{ }^{-}$. The gases resulting from the process are separated from the fluid at the gasliquid separator stage and vented into the atmosphere, whereas the liquid is returned to the BWP for a new cycle. The concern is that effluent from the gasliquid separator might transfer potentially harmful amounts of $\mathrm{NH}_{3}$ to an enclosed environment. This is the principal factor motivating the monitoring of $\mathrm{NH}_{3}$ concentration levels in the water recovery system gas exhaust.

The packed-bed reactor contains anaerobic bacteria that decompose organic molecules from wastewater collected from the donation center moving from the waste tank at a rate of $16 \mathrm{ml} / \mathrm{min}$. As a residual of this initial process, known as total organic carbon (TOC) reduction, an equilibrium amount of ammonia-ammonium ions dissolved in water is produced, along with other compounds, in particular $\mathrm{CO}_{2}$. The nitrifier consists of a $4000-\mathrm{ft}-(1219-\mathrm{m}-)$ long coil of 0.25 -in. $(0.64 \mathrm{~cm})$ polypropylene tubing, 
treated on the inner surface with a biofilm of aerobic, nitrifying bacteria, which in the presence of air produce the reaction

$$
\mathrm{NH}_{3} \stackrel{\mathrm{O}_{2}}{\longrightarrow} \mathrm{NO}_{2}^{-} \stackrel{\mathrm{O}_{2}}{\longrightarrow} \mathrm{NO}_{3}^{-} .
$$

The $\mathrm{NH}_{3} / \mathrm{NH}_{4}{ }^{+}$concentration level indicates the efficiency of the nitrifying process in the BWP, once the nitrifier loop is set in operation. If the $\mathrm{pH}$ is known, the total $\mathrm{NH}_{3} / \mathrm{NH}_{4}{ }^{+}$concentration can be calculated from measurements of the $\mathrm{NH}_{3}$ concentration in the gas stream. The $\mathrm{CO}_{2}$ concentration measurement also gives a quantitative indication of the conversion of TOC in the system, which is an important parameter to determine the quality of the water that has been recycled. At the end of the loop, a fraction $(1 / 20$ th) of the recycled water is extracted from the BWP for postprocessing, whereas the rest is sent back into the packed-bed reactor. To keep ammonia levels in the effluent gas low, nitric acid is added as necessary to the BWP waste tank to maintain a $\mathrm{pH}$ of 7.5. The gaseous residual is vented through the exhaust line into the atmosphere. Water vapor is removed from the gas exhaust by a water condenser.

The diode-laser-based sensor was connected to the exhaust line after the water condenser, as shown in Fig. 2, and placed $\sim 3 \mathrm{~m}$ away from the BWP unit. We used approximately $6 \mathrm{~m}$ of Teflon tubing [0.25 in. $(0.64 \mathrm{~cm})]$ to satisfy NASA JSC safety protocols. A glass flask $(\sim 150 \mathrm{ml})$ was inserted along the Teflon line to collect any remaining water droplets in the gas. The flow rate to the multipass cell was adjusted to be less than the exhaust line rate to ensure sampling of the BWP and not outside air. For this purpose, a flow meter and controller were installed immediately upstream from the sensor to measure a constant flow rate of 10 SCCM (SCCM denotes cubic centimeters per minute at STP), well below the bioreactor exhaust rates of several hundreds of SCCM.

\section{Results and Discussion}

\section{A. Calibration and Fitting Routines}

A convenient method for determining the accuracy of concentration measurements of the sensor system was to measure the absorption of a 100-Torr sample of $\mathrm{CO}_{2}$, which resulted in a concentration of $97.6 \%$ when we used HITRAN96 line-strength and pressure-broadening coefficients and assumed an optical path length of $36 \mathrm{~m}$. When we measured the same sample using a second multipass cell and a $2.0-\mu \mathrm{m}$ diode laser, accessing a $\mathrm{CO}_{2}$ line whose linestrength and pressure-broadening coefficient were characterized independently, ${ }^{13,14}$ the $\mathrm{CO}_{2}$ concentration was found to be $100 \pm 5 \%$. Thus the accuracy of the laser-based ammonia sensor reported in this study is better than $5 \%$.

A second calibration procedure was performed with a calibrated ammonia sample $\left(100 \pm 2 \mathrm{ppm}\right.$ in $\left.\mathrm{N}_{2}\right)$ that we diluted with $\mathrm{N}_{2}$ to a nominal 5-ppm mixture using a gas mixer capable of controlled temperature, pressure, and flow-rate operating conditions. $\mathrm{NH}_{3}$ concentration measurements were performed simultaneously with the overtone-based sensor operating at $1.53 \mu \mathrm{m}$ and with a quantum-cascade laser-based sensor that uses the fundamental $\mathrm{NH}_{3}$ absorption band $\nu_{2}$ at $10.07 \mu \mathrm{m} .{ }^{15}$ The results for the two procedures are shown in Fig. 3 and demonstrate an agreement of better than 5\% between the two independent measurements. These are within the standard deviation of the overtone measurements of \pm 0.2 ppm, or $7 \%$. We obtained the fundamental absorption measurement using a line strength available from the HITRAN96 database, whereas the overtone measurement uses a value reported in Ref. 7. Both measurements yield values below the expected $\mathrm{NH}_{3}$ concentration, most likely because ammonia sticks to the stainless-steel surface of the gas mixer, and insufficient time elapsed to reach a steady state in adsorption and desorption.

The real-time fitting routine implemented in LabVIEW has been reported elsewhere, ${ }^{16}$ and only minor software modifications were required for this study to process the logarithmic signal from the detector operating in the autobalance mode. Figure 4 illustrates how a direct transmission spectrum from the logarithmic output of the Nirvana detector, operating in autobalance mode, is obtained. A third-order polynomial is fitted to the baseline of the absorption scan, as shown in Fig. 4(a). If a voltage $V^{*}(v)$ is assigned to the baseline values, and the logarithmic signal values are assigned a voltage $V(v)$, then the corresponding optical transmission for a specified frequency value $T(v)$, in percent, is given by ${ }^{17}$

$$
T(\nu)=100 \frac{\exp \left[-\frac{A}{T} V^{*}(v)\right]+1}{\exp \left[-\frac{A}{T} V(v)\right]+1},
$$

where $A$ is a constant determined by the gain of the detector amplifier $(\mathrm{A}=273 \mathrm{~K} / \mathrm{V})$ and $T$ is the temperature of the photodetector (operating at $300 \mathrm{~K}$ ). The result of this operation is depicted in Fig. 4(b). This procedure provides a balanced transmission spectrum and simultaneously corrects for the baseline of the absorption signal. To this spectrum (after we divide by 100 and take the natural logarithm), an absorption line-shape function is fitted to obtain the gas concentration as described below. The convenience of this procedure is that only one detection channel is needed in this configuration to account for both the signal and the reference signals from the photodetector.

The fit employs a nonlinear, least-squares Levenberg-Marquardt algorithm and uses a given absorption profile to fit the data. Because the pressure regime of operation (100 Torr) lies between the predominantly Doppler and pressure-broadened regimes, a Voigt profile with fixed pressure broadening and Doppler width was used. A Lorentz function overestimates the area under the curve by $\sim 6 \%$. Figure 5 


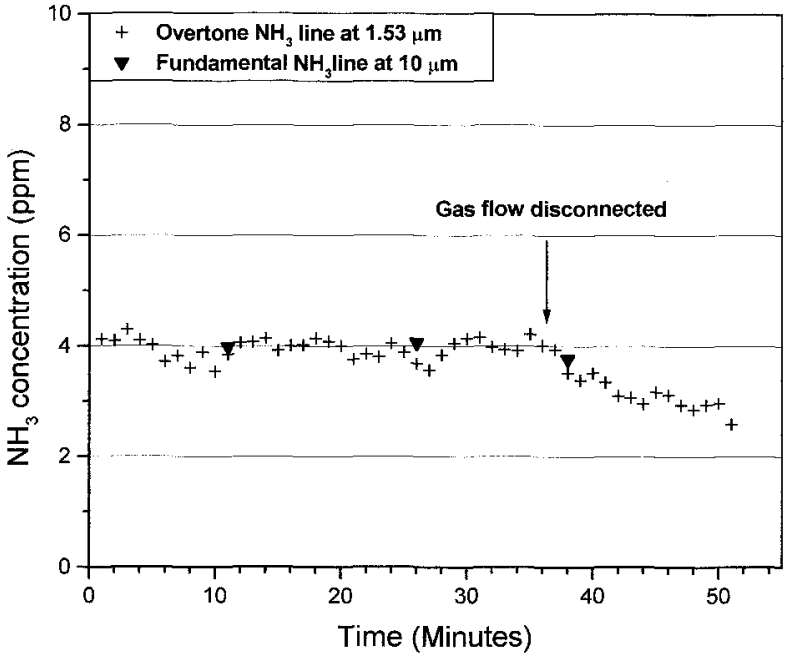

Fig. 3. Intercomparison of concentration measurements of a 4-ppm $\mathrm{NH}_{3}$ in a $\mathrm{N}_{2}$ mixture with a $1.53-\mu \mathrm{m}$ DFB diode laser and a single-frequency quantum-cascade laser-based sensor operating at $10.07 \mu \mathrm{m}$.

shows a typical absorption spectrum obtained, where we removed the baseline using a third-order polynomial and to which we fitted a Voigt profile, ${ }^{18,19}$ with a linewidth of $0.027 \mathrm{~cm}^{-1}$ and a pressure-broadening contribution of $0.020 \mathrm{~cm}^{-1}$. Because of pressure fluctuations in the bioreactor exhaust of \pm 2 Torr, not accounted for by the fitting routine, and the fluctuations observed in the $\mathrm{CO}_{2}$ concentration from the exhaust gases of $\pm 2 \%$, the linewidth of the ammonia absorption peaks is expected to fluctuate by approximately $\pm 0.002 \mathrm{~cm}^{-1} .5,6,20$ This introduces an error for the ammonia concentration measurement in the LabVIEW calculation routine of $4 \%$. The residual of the Voigt fit yields an uncertainty level for a single measurement (with 500 averages) of $\pm 0.01 \%$ absorp-
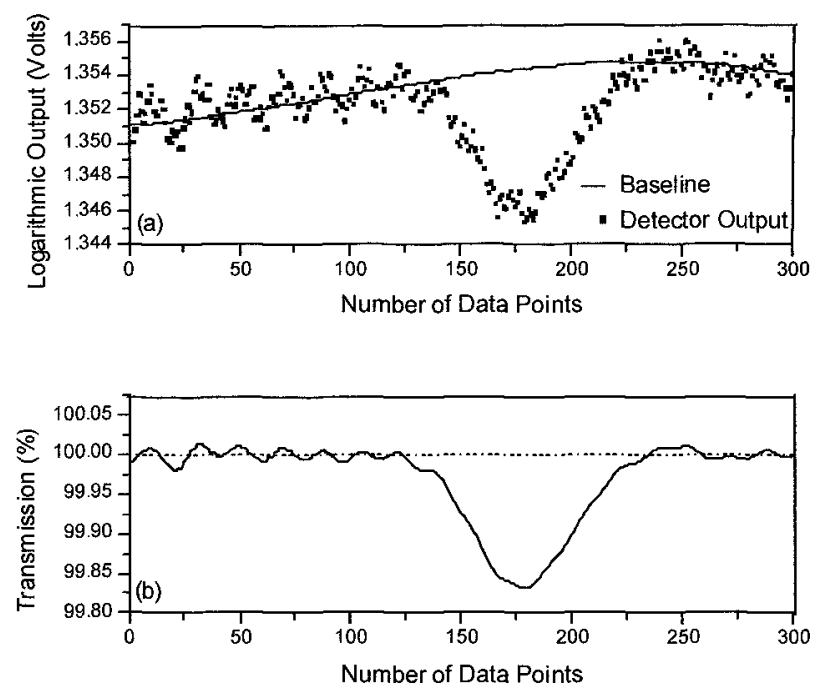

Fig. 4. Algorithm developed to obtain the transmission spectrum (\%) from the logarithmic output of the Nirvana detector in the autobalanced mode. See text for details.
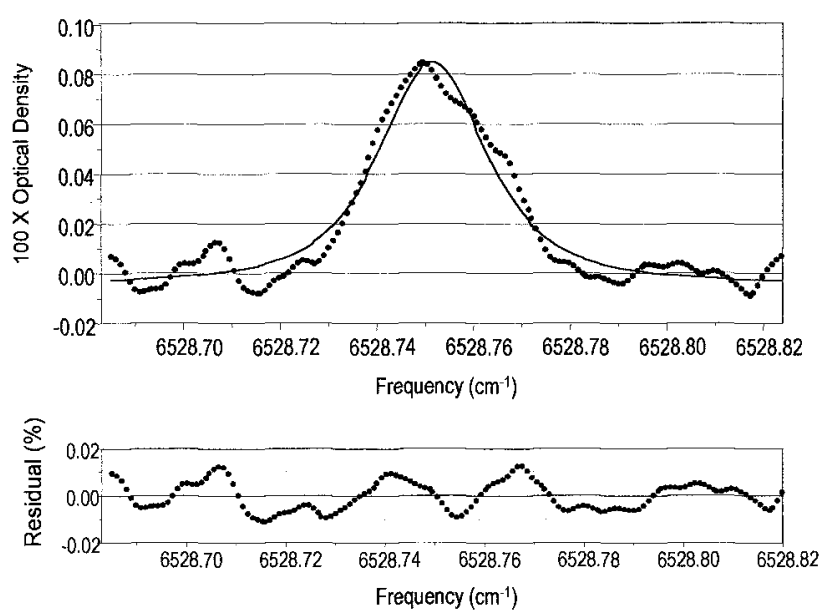

Fig. 5. Typical $\mathrm{NH}_{3}$ absorption line at $6528.76 \mathrm{~cm}^{-1}$ observed from the NASA JSC bioreactor, with the detector operating in autobalance mode. The residual obtained from the Voigt line-shape fit is shown below the $\mathrm{NH}_{3}$ spectrum and indicates a limiting detection sensitivity of $10^{-4}$ optical density [optical density is given by $-\ln (\mathrm{I} /$ $\left.\mathrm{I}_{0}\right)$ ]. The $\mathrm{NH}_{3}$ concentration from the Voigt fit is $1.4 \mathrm{ppm}$.

tion [note that $100 \times \ln \left(I / I_{0}\right)$ is equivalent to percent absorption for small absorptions]. The rms uncertainty level is then $0.014 \%$ absorption. From Fig. 5, where a peak absorption of $0.085 \%$ corresponds to 1.4 ppm of $\mathrm{NH}_{3}$, it can be seen that detection with a signalto-noise ratio of 3 corresponds to a concentration of 0.7 ppm (i.e., $0.7 \pm 0.12 \mathrm{ppm}$ ). This is the minimum concentration that can be measured reliably with the reported gas sensor design. Optical fringes from interference effects introduced by the multipass cell limit the sensitivity and are the primary source of uncertainty in the ammonia concentration values reported. Other groups implementing a dual-beam autobalancing technique like the one reported in this study have obtained similar sensitivity values. ${ }^{21,22}$ To our knowledge, the sensitivity reported here is the best obtained so far in a field application for $\mathrm{NH}_{3}$ measurements by use of overtone absorption spectroscopy, taking advantage of recent advances in singlefrequency DFB diode-laser and optical fiber technology.

We obtained simultaneous measurements of $\mathrm{NH}_{3}$ and $\mathrm{CO}_{2}$ concentrations by fitting the three lines $A$, $B$, and $C$ in real time as mentioned in Section 1 . This technique uses the fact that the three peaks can be obtained in a single diode-laser scan of $\sim 0.3 \mathrm{~cm}^{-1}$. The algorithm begins with a Voigt fit on peak $A$. With the $\mathrm{NH}_{3}$ concentration thus obtained, peak $B$ is modeled and subtracted from the absorption feature. The remaining absorption signal at the location of peaks $B$ and $C$ is fitted again to a Voigt profile, which yields the $\mathrm{CO}_{2}$ concentration. This algorithm removes the problem of having to fit the two peaks that overlap $B$ and $C$ simultaneously. It also allows for the subtraction of the baseline in two separate sections, one for line $A$ in the first step and the other for lines $B$ and $C$ in the second step. This technique eliminates unwanted effects of spurious baseline fea- 

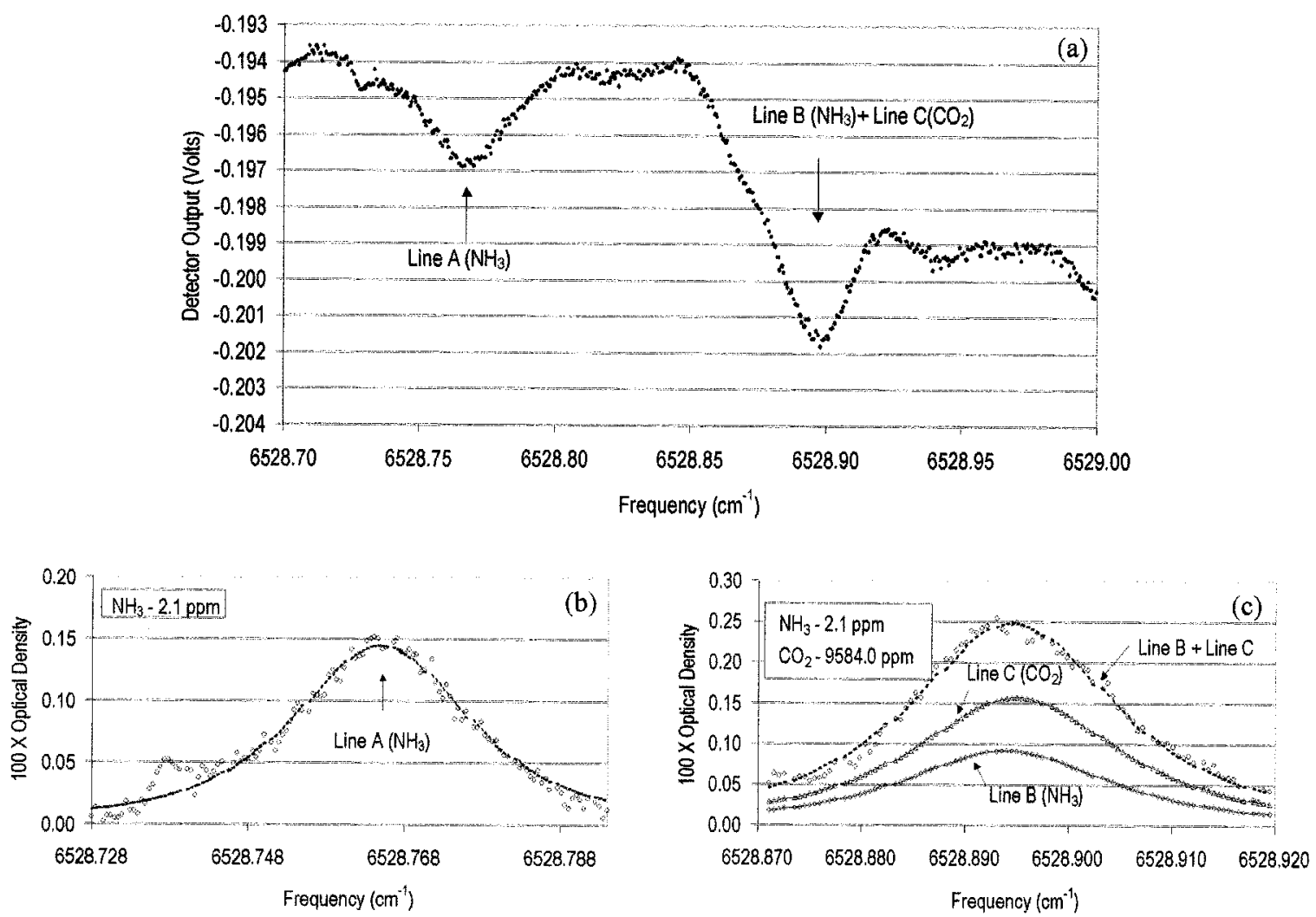

Fig. 6. Measured $\mathrm{NH}_{3}$ and $\mathrm{CO}_{2}$ absorption lines listed in Table 1, centered at $6528.8 \mathrm{~cm}^{-1}$, observed from the BWP vent gases. (a) Raw data obtained from a typical laser scan over $\sim 0.3 \mathrm{~cm}^{-1}$. The two absorption features at 6528.76 and $6528.89 \mathrm{~cm}^{-1}$ are clearly visible. (b) Result of the two-step fitting routine applied to line $A$, in which a $\mathrm{NH}_{3}$ concentration of $2.1 \mathrm{ppm}$ is obtained. (c) Fit performed on the absorption feature that includes both lines $B$ and $C$, showing a $\mathrm{CO}_{2}$ concentration of $0.9 \%$.

tures that may occur between the two absorption lines. Figure 6 shows an absorption spectrum of the two $\mathrm{NH}_{3}$ and the $\mathrm{CO}_{2}$ lines listed in Table 1, obtained in a single diode-laser scan. The baseline subtraction obtained with this algorithm for the peaks $A, B$, and $C$ yields a fit residual of less than $\pm 0.02 \%$ absorption within the peaks. Such a residual would not have been realized if a single baseline had been fitted across the entire scan range.

\section{B. Bioreactor Measurements}

$\mathrm{NH}_{3}$ concentration measurements were performed at NASA JSC for a period of 13 days, from 25 August to 7 September 2000. Figure 7 shows the ammonia concentration as a function of time, measured during the first three days of data collection (25-28 August 2000). The $\mathrm{NH}_{3}$ concentration fluctuates in periods of $\sim 10 \mathrm{~h}$, ranging from levels below the sensitivity of the instrument and up to $5.6 \mathrm{ppm}$. Figure 8 shows the overall time history of the ammonia measurements performed on the bioreactor system, except for a three-day period from 30 August to 1 September 2000 , when the bioreactor was monitored by a $2.0-\mu \mathrm{m}$ diode laser from Stanford University. ${ }^{14}$ Critical biochemical procedures taken on the different parts of the BWP by NASA personnel are indicated. The standard deviation of the autobalanced output data is calculated to be $0.1 \mathrm{ppm}$, whereas for the linear case it increases to $0.2 \mathrm{ppm}$. Such a difference is expected because the autobalanced scheme minimizes most common sources of noise in both the signal and the reference arms of the laser beam. In particular, laser amplitude fluctuations produced by electronic noise from the power supplies and temperature drifts are removed. As mentioned above, the linear output measurements were averaged for 1000 scans, as com-

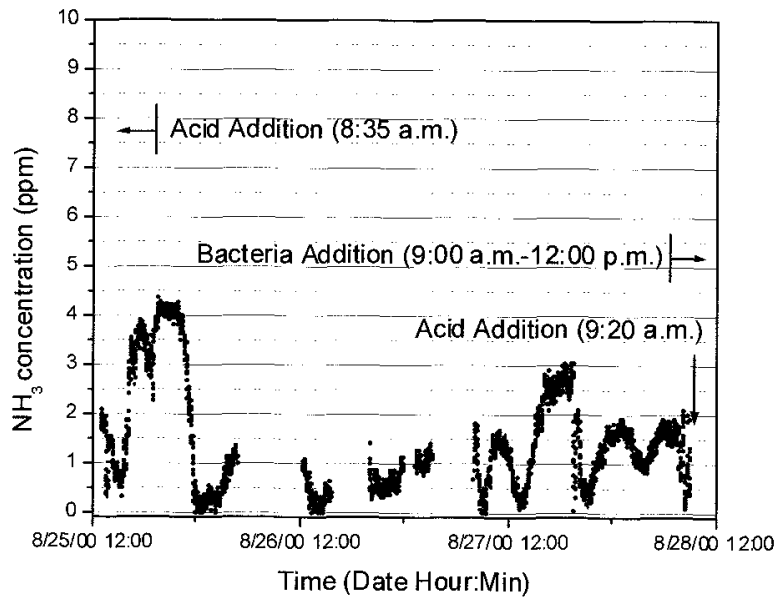

Fig. 7. Time history of $\mathrm{NH}_{3}$ concentration from NASA JSC bioreactor vent gases for a three-day period. 


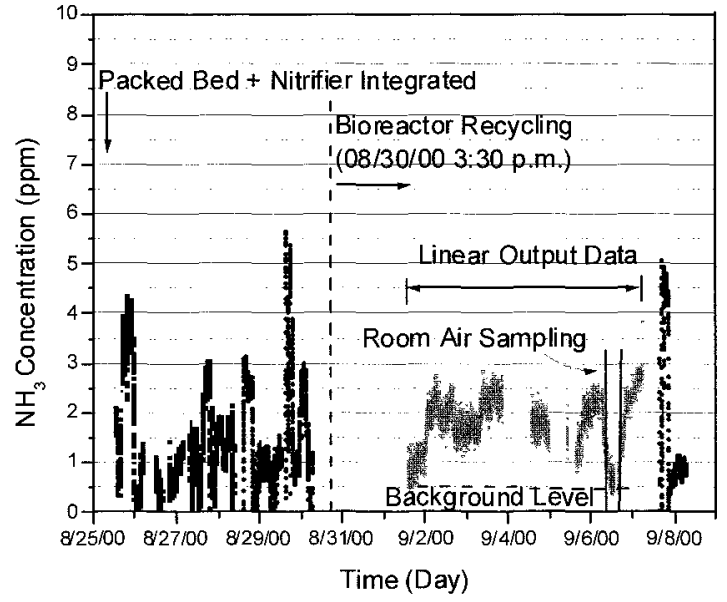

Fig. 8. Ammonia concentration measurements for an 11-day period. Filled circles correspond to data points obtained in the autobalance mode, and triangles correspond to data obtained in the linear mode of the detector. Measured ammonia levels never exceeded $5.6 \mathrm{ppm}$ during this period. A three-day gap occurred when a $2-\mu \mathrm{m}$ DFB diode laser ${ }^{14}$ was used in the sensor instead of the $1.53-\mu \mathrm{m}$ diode laser.

pared with only 500 scans for the autobalanced measurements. The main sources of uncertainty in this experiment are the optical fringes produced in the multipass cell. The autobalance technique does not remove the fringes because they do not affect the signal and reference beams simultaneously. We performed a background ammonia concentration measurement by disconnecting the system from the bioreactor and sampling room air. The $\mathrm{NH}_{3}$ background was measured to be $\sim 0.5 \mathrm{ppm}$ (see Fig. 8 ) and is due to the residual ammonia that has accumulated on the walls of the gas line from the BWP to the ammonia sensor. During the entire measurement period the ammonia levels never exceeded $5.6 \mathrm{ppm}$ after the packed-bed reactor and the nitrifier coils were integrated. The $\mathrm{NH}_{3}$ concentration fluctuated during the period (25-30 August) before the BWP was operated in the recycling mode. In this mode, no more wastewater samples were added and the ammonia levels decreased (shown in Fig. 8 and also verified in Fig. 13, Ref. 14).

$\mathrm{NH}_{4}{ }^{+}$aqueous-phase concentration measurements were performed once a day by NASA personnel using standard wet-chemical techniques. From this and the $\mathrm{pH}$ value of the aqueous solution, the concentration of $\mathrm{NH}_{3}$ in solution can be calculated. An estimate of the $\mathrm{NH}_{3}$ concentration in the gas phase was calculated with Henry's law. ${ }^{23}$ The resulting values are shown in Table 2, which is in agreement with the results obtained with the laser-based ammonia sensor. It is observed that, in general, the calculated values from the wet-chemical measurements are somewhat larger than the measured concentrations with the laser-based sensor. However, it should be noted that the wet-chemical measurements provide only an order-of-magnitude estimate of the overall ammonia concentration expected in the gas phase.
Table 2. Aqueous- and Gas-Phase $\mathbf{N H}_{3}$ Concentrations Calculated from Measurements of $\left[\mathrm{NH}_{4}{ }^{+}\right], \mathrm{pH}$, and with Henry's Law

\begin{tabular}{ccc}
\hline Date & $\begin{array}{c}\mathrm{NH}_{3} \text { Aqueous } \\
(\mathrm{mg} / \mathrm{l})\end{array}$ & $\begin{array}{c}\mathrm{NH}_{3} \text { Gas } \\
(\mathrm{ppm})\end{array}$ \\
\hline 25 Aug. & 32.5 & 13.0 \\
26 Aug. & 12.5 & 5.0 \\
27 Aug. & 8.7 & 3.5 \\
28 Aug. & 8.6 & 3.4 \\
29 Aug. & 20.7 & 8.3 \\
30 Aug. & 19.9 & 8.0 \\
31 Aug. & 10.0 & 4.0 \\
1 Sept. & 14.5 & 5.8 \\
2 Sept. & 6.1 & 2.4 \\
3 Sept. & 11.0 & 4.4 \\
4 Sept. & 5.2 & 2.1 \\
5 Sept. & 3.7 & 1.5 \\
6 Sept. & 4.4 & 1.8 \\
\hline
\end{tabular}

An accurate measurement would require a precise account of all the ions in the solution, the $\mathrm{pH}$ of the solution, and the variation of these quantities in the various subsystems of the bioreactor.

Figure 9 shows the simultaneous $\mathrm{NH}_{3}$ and $\mathrm{CO}_{2}$ concentration measurements for a portion of the overall measurement time, obtained when we applied the triple Voigt fit algorithm described in Section 3.A. The two measurements are clearly anticorrelated, which is to be expected from the fact that ammonia and carbon dioxide gas-phase concentrations should have opposite dependence on the $\mathrm{pH}$ in the BWP water solution. The $\mathrm{CO}_{2}$ concentration shown in Fig. 9 provides information that we can use to improve the BWP operation by monitoring the efficiency of the BWP in performing TOC reduction. Throughout the time periods when $\mathrm{CO}_{2}$ concentrations were measured, largely fluctuating values were obtained. $\mathrm{CO}_{2}$ levels from less than 1000 to 20,000 ppm were observed, with values decreasing after the BWP was set into its recycling mode on 30 August 2000.

\section{Conclusions}

We described the performance of a trace gas sensor based on overtone absorption spectroscopy at 1.53

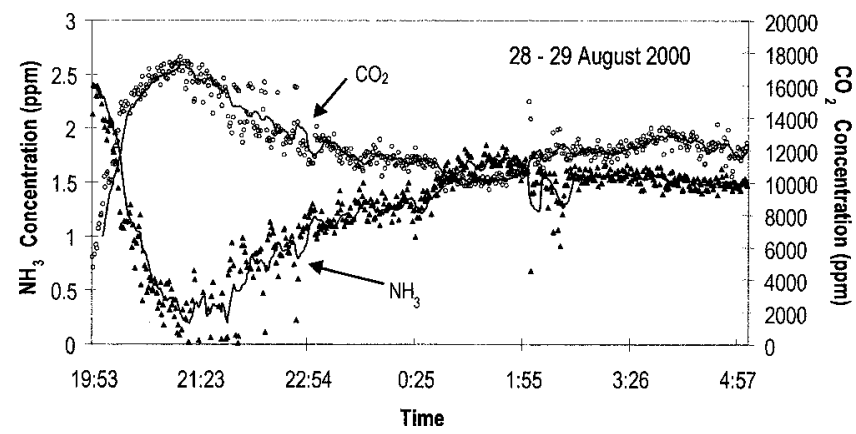

Fig. 9. Simultaneous $\mathrm{CO}_{2}$ and $\mathrm{NH}_{3}$ concentration measurements. The $\mathrm{CO}_{2}$ levels do not exceed $20,000 \mathrm{ppm}$. The time period can be related to the ammonia measurements reported in Fig. 7 . The continuous curves represent moving averages of ten data points for the two gases being measured. 
$\mu \mathrm{m}$, applied to ammonia and carbon dioxide detection in a bioreactor exhaust line, with a time resolution of $30 \mathrm{~s}$ and a sensitivity of $0.7 \mathrm{ppm}$ at a signal-to-noise ratio value of 3 . The advantages of this sensor compared with other methods are compactness, portability, simplicity of operation, and the ability to perform near-real-time measurements. The $\mathrm{NH}_{3}$ concentration measurements reveal a dynamic behavior of the bioreactor that could not be detected and measured otherwise. These measurements also indicate that, during the period of this study, ammonia emissions into the environment remained below harmful levels. ${ }^{24}$ This evaluation may have to be revised when longer periods of operation in a closed environment are considered. The ability to perform simultaneous $\mathrm{NH}_{3}$ and $\mathrm{CO}_{2}$ measurements in real-time has been demonstrated. A clear anticorrelation between the concentrations of these two gases is observed, which is in agreement with the expected operating conditions of the NASA JSC bioreactor.

The diode-laser-based ammonia sensor can be used in other applications, especially those with concentration levels of $1 \mathrm{ppm}$ and higher, that need to be monitored with a fast time response. Furthermore, other gases such as $\mathrm{CO}_{2}, \mathrm{HF}, \mathrm{HCl}, \mathrm{NO}, \mathrm{CH}_{4}$, and $\mathrm{H}_{2} \mathrm{O}$ can be monitored by the appropriate wavelength selection of the DFB diode laser or a tunable multiwavelength DFB diode-laser source, which provides additional wavelength channels for multispecies gas detection.

Funding for this project was provided by NASA, the Texas Advanced Technology Program, and the Welch Foundation. R. Claps thanks M. E. Webber of Stanford University for fruitful discussions on Voigt fitting routines. F. V. Englich and R. Claps also express their gratitude to the NASA JSC Crew and Thermal Systems Division personnel for providing the necessary logistic support to perform the bioreactor measurements. D. Leleux acknowledges the support by the NASA JSC Graduate Student Research Program.

\section{References}

1. M. Ohtsu, H. Kotani, and H. Tagawa, "Spectral measurements of $\mathrm{NH}_{3}$ and $\mathrm{H}_{2} \mathrm{O}$ for pollutant gas monitoring by $1.5 \mu \mathrm{m}$ InGaAs/InP lasers," Jpn. J. Appl. Phys. 22, 1553-1557 (1983).

2. M. Feher, P. A. Martin, A. Rohrbacher, A. M. Soliva, and J. P. Maier, "Inexpensive near-infrared diode-laser-based detection system for ammonia," Appl. Opt. 32, 2028-2030 (1993).

3. R. M. Mihalcea, M. E. Webber, D. S. Baer, R. K. Hanson, G. S. Feller, and W. B. Chapman, "Diode-laser absorption measurements of $\mathrm{CO}_{2}, \mathrm{H}_{2} \mathrm{O}, \mathrm{N}_{2} \mathrm{O}$ and $\mathrm{NH}_{3}$ near $2.0 \mu \mathrm{m}$," Appl. Phys. B 67 (3), 283-288 (1998).

4. I. Linnerud, P. Kaspersen, and T. Jaeger, "Gas monitoring in the process industry using diode laser spectroscopy," Appl. Phys. B 67 (3), 297-305 (1998).

5. G. Modugno and C. Corsi, "Water vapour and carbon dioxide interference in the high sensitivity detection of $\mathrm{NH}_{3}$ with semiconductor diode lasers at $1.5 \mu \mathrm{m}$," Infrared Phys. Technol. 40, 93-99 (1999).

6. L. Lundsberg-Nielsen, F. Hegelund, and F. M. Nicolaisen, "Analysis of the high-resolution spectrum of ammonia $\left({ }^{14} \mathrm{NH}_{3}\right)$ in the near-infrared region, $6400-6900 \mathrm{~cm}^{-1}$," J. Mol. Spectrosc. 162, 230-245 (1993).

7. M. E. Webber, D. S. Baer, and R. K. Hanson, "Ammonia mon- itoring near $1.5 \mu \mathrm{m}$ with diode laser absorption sensors," Appl. Opt. 40, 2031-2042 (2001).

8. P. C. D. Hobbs, "Ultrasensitive laser measurements without tears," Appl. Opt. 36, 903-920 (1997).

9. Y. He and B. J. Orr, "Ringdown and cavity-enhanced absorption spectroscopy using a continuous-wave tunable diode laser and a rapidly swept optical cavity," Chem. Phys. Lett. 319, 131-137 (2000).

10. R. Peeters, G. Berden, A. Apituley, and G. Meijer, "Open-path trace gas detection of ammonia based on cavity-enhanced absorption spectroscopy," Appl. Phys. B 71, 231-236 (2000).

11. E. V. Stepanov, P. V. Zyrianov, and A. N. Khusnutdinov, "Multicomponent gas analyzers based on tunable diode lasers," in Advanced Technologies for Environmental Monitoring and Remediation, T. Vo-Dinh, ed., Proc. SPIE 2835, 271-281 (1996).

12. L. S. Rothman, C. P. Rinsland, A. Goldman, S. T. Massie, D. P. Edwards, J.-M. Flaud, A. Perrin, C. Camy-Peyret, V. Dana, J.-Y. Mandin, J. Schroeder, A. McCann, R. R. Gamache, R. B. Wattson, K. Yoshino, K. V. Chance, K. W. Jucks, L. R. Brown, V. Nemtchinov, and P. Varanasi, "The HITRAN molecular spectroscopic database and HAWKS (HITRAN atmospheric workstation): 1996 edition,” J. Quant. Spectrosc. Radiat. Transfer 60, 665-710 (1998).

13. M. E. Webber, S. Kim, S. T. Sanders, D. S. Baer, R. K. Hanson, and Y. Ikeda, "In situ combustion measurements of $\mathrm{CO}_{2}$ by use of a distributed-feedback diode-laser sensor near $2.0 \mu \mathrm{m}$," Appl. Opt. 40, 821-828 (2001).

14. M. E. Webber, R. Claps, F. V. Englich, F. K. Tittel, J. B. Jeffries, and R. K. Hanson, "Measurements of $\mathrm{NH}_{3}$ and $\mathrm{CO}_{2}$ with distributed-feedback diode lasers near $2.0 \mu \mathrm{m}$ in bioreactor vent gases," Appl. Opt. 40, (2001). (LP 17579)

15. A. A. Kosterev, F. K. Tittel, C. Gmachl, F. Capasso, D. L. Sivco, J. N. Baillargeon, A. L. Hutchinson, and A. Y. Cho, "Trace-gas detection in ambient air with a thermoelectrically cooled, pulsed quantum-cascade distributed-feedback laser," Appl. Opt. 39, 6866-6872 (2000).

16. D. G. Lancaster, D. Richter, R. F. Curl, and F. K. Tittel, "Realtime measurements of trace gases using a compact differencefrequency-based sensor operating at $3.5 \mu \mathrm{m}$," Appl. Phys. B 67, 339-345 (1998).

17. K. L. Haller and P. C. D. Hobbs, "Double beam laser absorption spectroscopy: shot noise-limited performance at baseband with a novel electronic noise canceller," in Optical Methods for Ultrasensitive Detection and Analysis: Techniques and Applications, B. L. Fearey, ed., Proc. SPIE 1435, 298-309 (1991).

18. E. E. Whiting, "An empirical approximation to the Voigt profile," J. Quant. Spectrosc. Radiat. Transfer 8, 1379-1384 (1968).

19. D. J. Brassington, "Tunable diode laser absorption spectroscopy for the measurement of atmospheric species," in Spectroscopy in Environmental Science, R. J. H. Clark and R. E. Hester, eds. (Wiley, New York, 1995), pp. 85-147.

20. C. H. Townes and A. L. Schawlow, Microwave Spectroscopy (McGraw-Hill, New York, 1955), Chap. 13, p. 364, Table 13.4.

21. G. Durry, I. Pouchet, N. Amarouche, T. Danguy, and G. Megie, "Shot-noise-limited dual-beam detector for atmospheric tracegas monitoring with near-infrared diode lasers," Appl. Opt. 39, 5609-5619 (2000).

22. G. Monlux, J. A. Brand, P. Zmarzly, M. Walker, K. W. Groff, G. J. Fetzer, N. Goldstein, F. Bien, S. C. Richtsmeister, and J. Lee, "In-situ ammonia analyzer for process control and environmental monitoring," in Advanced Technologies for Environmental Monitoring and Remediation, T. Vo-Dinh, ed., Proc. SPIE 2835, pp. 236-247 (1996).

23. P. Brimblecombe and S. L. Clegg, "Solubility of ammonia in pure aqueous and multicomponent solutions," J. Phys. Chem. 93, 7237-7248 (1989).

24. J. C. Graf, NASA JSC Crew and Thermal Systems Division, Houston, Tex. (personal communication, September 2000). 